\title{
Pediatric sellar tumors: diagnostic procedures and management
}

\author{
Jay Jagannathan, M.D., Aaron S. Dumont, M.D., John A. Jane JR., M.D., \\ AND EDWARD R. LAWS JR., M.D. \\ Department of Neurological Surgery, University of Virginia Health Science Center, Charlottesville, \\ Virginia
}

\begin{abstract}
The diagnosis and management of pediatric sellar lesions is discussed in this paper. Craniopharyngiomas account for the majority of pediatric sellar masses, and pituitary adenomas are extremely uncommon during childhood. The diagnosis of sellar lesions involves a multidisciplinary effort, and detailed endocrinological, ophthalmological, and neurological testing is critical in the evaluation of a new sellar mass. The management of pituitary adenomas varies depending on the entity. For most tumors other than prolactinomas, transsphenoidal resection remains the mainstay of treatment. Less invasive methods, such as endoscopic transsphenoidal surgery and stereotactic radiosurgery, have shown promise as primary and adjuvant treatment modalities, respectively.
\end{abstract}

\section{KEY WORDS • pituitary adenoma • craniopharyngioma • pediatric tumor • sellar tumor - children}

Pediatric sellar and parasellar lesions include a diverse group of tumors. More than $90 \%$ of purely intrasellar tumors are pituitary adenomas, although dysembryogenic lesions (that is, Rathke cleft cysts) also occur. Suprasellar lesions include craniopharyngiomas, germinomas, dermoid/epidermoid cysts, lipomas, teratomas, and hamartomas. Other sellar tumors such as meningiomas or gliomas are not usually symptomatic during childhood and adolescence. Over the last 30 years, significant advances in microneurosurgery, neuroimaging, and molecular biology have significantly changed the diagnosis and management of sellar lesions. In this review we focus on current concepts in the understanding of these diverse pathological entities.

\section{EPIDEMIOLOGY}

\section{Prevalence of Craniopharyngiomas}

Craniopharyngiomas account for the overwhelming majority $(\sim 90 \%)$ of neoplasms arising in the pituitary region (other than pituitary adenomas). ${ }^{11}$ Most of these lesions arise from the Rathke pouch-a cystic diverticulum that originates from the roof of the stomodeum. Craniopharyngiomas constitute between 3 and 5\% of all intracranial expanding lesions and account for $6 \%$ of all expanding lesions during the pediatric years. ${ }^{34}$ Patients with these tumors show a bimodal age distribution during the first and second decade of life and then again in the fifth ${ }^{55}$ there is with no apparent predilection for either sex. ${ }^{16}$ Most originate in the intrasellar and suprasellar region (70\%) with

Abbreviations used in this paper: ACTH = adrenocorticotropic hormone; $\mathrm{CD}=$ Cushing's disease; $\mathrm{FSH}=$ follicle-stimulating hormone; $\mathrm{GH}=$ growth hormone; $\mathrm{LH}=$ luteinizing hormone; $\mathrm{MR}=$ magnetic resonance; $\mathrm{PRL}=$ prolactin; $\mathrm{TSH}=$ thyroid-stimulating hormone. suprasellar localizations (20\%) or solely intrasellar lesions $(10 \%)$ occurring less frequently. ${ }^{4,9}$

\section{Prevalence of Pituitary Adenomas}

Pituitary adenomas are the most common cause of pituitary disease in adults but rarely present during childhood (although the incidence increases during adolescence). ${ }^{15,44}$ Pituitary adenomas constitute less than $3 \%$ of supratentorial tumors in children, with a mean annual incidence of approximately 0.1 per million children. ${ }^{8}$ Pituitary carcinomas are rare in adults and extremely rare in children..$^{50}$

An increased prevalence of pituitary adenomas in female patients has been reported, ${ }^{8,44}$ which most likely reflects the relative predominance of the two main types of adenomas (PRL- and ACTH-secreting adenomas). Prolactinomas are the most frequent adenoma subtype in children, followed by the corticotropin-secreting tumors and the somatotropinomas. Nonfunctioning pituitary adenomas, that is, null cell and gonadotropin-secreting adenomas, are very rare in children, accounting for only 3 to $6 \%$ of all pituitary tumors. ${ }^{1,8,44}$ As with adults, the presenting symptoms of pediatric pituitary tumors are generally related to endocrine dysfunction, such as growth delay and primary amenorrhea, rather than to mass effect. ${ }^{1}$

Prolactin-Secreting Adenomas. Prolactinomas are the most frequent pituitary tumors in childhood and in adulthood, and their frequency varies with age and sex, occurring most often in women between 20 and 50 years of age. ${ }^{55}$

Adrenocorticotropic Hormone-Secreting Adenomas. In children between 11 and 15 years of age, ACTH-secreting adenomas are the most frequent cause of adrenal hyperfunction and the second most frequent pituitary adenoma after prolactinomas. ${ }^{31} \mathrm{~A}$ macroadenoma is rarely the cause of $\mathrm{CD}$ in children. ${ }^{46}$ 
Growth Hormone-Secreting Adenomas. In adulthood, these adenomas have a prevalence of 50 to 80 cases per million people; ${ }^{44}$ gigantism, by contrast, is extremely rare, with approximately 100 reported cases to date. ${ }^{23}$ In childhood, GH-secreting adenomas account for 5 to $15 \%$ of all pituitary adenomas. In less than $2 \%$ of the cases, excessive $\mathrm{GH}$ secretion is caused by a hypothalamic or ectopic GH releasing hormone-producing tumor (that is, a bronchial or pancreatic carcinoid).

Thyroid Stimulating Hormone-Secreting Adenomas. This tumor type is rare in adulthood and even rarer in childhood and adolescence, with only a few case reports in the literature. ${ }^{6}$ It is frequently a macroadenoma presenting with mass effect symptoms such as headache and visual disturbance, together with various symptoms and signs of hyperthyroidism. The TSH-secreting adenomas must be differentiated from thyroid hormone resistance. ${ }^{6,10}$ In most cases, the classic criteria of lack of TSH response to TRH stimulation, elevation of serum alpha-subunit levels, and a high alpha-subunit/TSH ratio, along with a pituitary mass on MR images, are diagnostic of TSH-secreting adenoma.

Gonadotropin-Staining Adenomas. The incidence of FSHand LH-secreting tumors with a clinical picture of hormone hypersecretion is very rare in the pediatric population. ${ }^{3,32}$

\section{CLINICAL PRESENTATION AND DIAGNOSTIC TESTS}

\section{Diagnostic Criteria for Craniopharyngiomas}

Neurological disturbances, such as headache and visual field defects, along with manifestations of endocrine deficiency such as growth retardation and delayed puberty are the common presenting symptoms of craniopharyngiomas. These tumors can stretch the diaphragma sellae and cause headaches. ${ }^{43}$ Obstruction of the cerebral aqueduct and the foramen of Monro may also occur, making a shunt necessary. ${ }^{34,43}$ At diagnosis, endocrine dysfunction is found in up to $80 \%$ of patients..$^{55}$ Reduced GH secretion is the most frequent endocrinopathy and can be present in up to $75 \%$ of patients. This is followed by FSH/LH deficiency, which can be seen in $40 \%$ of patients, and then ACTH and TSH deficiency in $25 \% .^{53}$

Despite the fact that craniopharyngiomas are frequently large at presentation, the pituitary stalk is usually not disrupted, and hyperprolactinemia secondary to pituitary stalk compression is found in only $20 \%$ of patients. Diabetes insipidus is relatively uncommon, occurring in 9 to $17 \%$ of patients. ${ }^{55}$ The recent availability of high-resolution MR imaging has greatly improved the visualization and radiological diagnosis of craniopharyngiomas. ${ }^{27}$

The neuroradiological diagnosis of craniopharyngiomas is based on the features of the lesion itself and on its relationship with the surrounding structures. ${ }^{25}$ The diagnosis is mainly based on the three characteristic components of the tumor: cystic, solid, and calcified. ${ }^{44,52}$ The cystic component constitutes the most important part of the tumor, and shows variable signal depending on the chemical-physical properties of its content. ${ }^{51} \mathrm{~A}$ fluid content will appear hypointense in $\mathrm{T}_{1}$-weighted and hyperintense in $\mathrm{T}_{2}$-weighted images, whereas a lipid (due to cholesterol), methemoglobin, or protein content will appear as hyperintense in $\mathrm{T}_{1}$ and $\mathrm{T}_{2}$ se- quences. The solid portion has an isointense signal in $\mathrm{T}_{1^{-}}$ and a hyperintense signal in $\mathrm{T}_{2}$-weighted images with an enhancement after $\mathrm{Gd}$, at variance with the cystic component. Nevertheless, contrast enhancement is not a consistent feature. ${ }^{52}$ Calcifications can appear as areas of low signal in all sequences, but are generally visualized better with computerized tomography scans..$^{24,44,52}$

\section{Criteria for PRL-Secreting Adenomas}

Prolactin-secreting adenomas are usually diagnosed at the time of puberty or in the postpubertal period, ${ }^{14,21}$ and clinical manifestations vary depending on the age and sex of the child. Girls of prepubertal age generally present with a combination of headache, visual disturbances, growth failure, and primary amenorrhea. The differential diagnosis of hyperprolactinemia should consider any process interfering with dopamine synthesis, its transport to the pituitary gland, or its action at lactotrophic dopamine receptors. A single measurement of PRL levels is unreliable because PRL secretion is markedly influenced by physical and emotional stress. To obtain a diagnostic value of PRL concentrations, at least three to six samples are necessary, with the mean value taken into consideration.

\section{Criteria for $C D$}

The clinical manifestations of CD are mostly the consequence of excessive cortisol production. The clinical presentation is highly variable, with signs and symptoms that can range from subtle to obvious. The diagnosis is generally delayed because a decrease in growth rate may be the only symptom for a long time. Growth failure in patients with CD may be due to a decrease of free insulin-like growth factor-I levels and/or a direct negative effect of cortisol on the growth plate. ${ }^{41}$

Other physical manifestations of $\mathrm{CD}$ include facial plethora; atrophic striae in the abdomen, legs, and arms; muscular weakness; hypertension; and osteoporosis. Results of bone mineral density or bone metabolism testing in children with $\mathrm{CD}$ have been reported only in some patients, and marked osteopenia was also found in affected children. ${ }^{41}$ Recent reports indicate that a long period of time (often $>2$ years) is necessary to restore bone mass after the cure of $\mathrm{CD}$, so other therapeutic approaches may be indicated to limit bone loss and/or accelerate bone recovery in these patients. ${ }^{20}$

Children with CD may also have impaired carbohydrate tolerance (although diabetes mellitus is uncommon). Excessive adrenal androgens may cause acne and excessive hair growth, or premature sexual development in the first decade of life. On the other hand, hypercortisolism may cause pubertal delay in adolescent patients. Peculiarly, young patients with $\mathrm{CD}$ may present with neuropsychiatric symptoms that differ from those of adult patients. Frequently they tend to be obsessive and are high performers at school. ${ }^{41}$

The differential diagnosis of CD includes adrenal tumors, ectopic ACTH production (rare in the pediatric population), and ectopic CRH-producing tumors. In a child/adolescent with suspected $\mathrm{CD}$, the diagnosis is based on measurement of basal and stimulated levels of cortisol and ACTH. Measurement of 24-hour urinary free cortisol is elevated, and a low dose of dexamethasone at midnight does 
not induce suppression of morning serum cortisol concentrations ${ }^{46}$ Suppression of the spontaneous circadian variations of serum cortisol is another feature of CD. Suppression of cortisol by more than 50\% after administration of high-dose dexamethasone given at midnight will confirm that hypercortisolism is due to an ACTH-secreting pituitary adenoma. ${ }^{20,41,46}$

All patients with suspected CD should undergo pituitary MR imaging with the administration of Gd contrast. Nevertheless, ACTH-secreting pituitary adenomas are significantly smaller than all other types of adenomas, and therefore even high-quality pituitary MR images may fail to visualize the tumor. In some cases, the diagnosis of CD must be made based on the initial clinical and laboratory data.

For cases in which the diagnosis of CD is unclear, inferior petrosal sinus sampling can have a high specificity, but it carries a high rate of false-positive results. ${ }^{38,49}$ This procedure can also be difficult in children, both from a technical standpoint and because of the risk of morbidity from surgery and anesthesia. ${ }^{37}$ If a patient without anomalous venous drainage patterns exhibits a lateralizing ACTH gradient of 2:1 or greater, ${ }^{37,38}$ removal of the appropriate half of the anterior pituitary gland will be curative in $80 \%$ of cases. Kunwar and Wilson ${ }^{33}$ reported that in the presence of negative findings on surgical exploration, the use of inferior petrosal sinus sampling as a guide to the localization of a pituitary adenoma can be successful and curative.

\section{Criteria for GH-Secreting Adenomas}

In adults, chronic GH hypersecretion causes acromegaly, which is characterized by hyperostosis. In children and adolescents it leads to gigantism because of associated secondary hypogonadism, which delays epiphysial closure, thus allowing long-bone growth. The two disorders may be considered part of a spectrum of GH excess, with principal manifestations determined by the developmental stage during which such excess originates. ${ }^{17}$ Supporting this model has been the observation of clinical overlap between the two entities, with approximately $10 \%$ of patients with acromegaly exhibiting tall stature,,$^{33}$ and the majority of those with gigantism eventually demonstrating features of acromegaly. ${ }^{18}$

The diagnosis of acromegaly and gigantism is usually clinical and can be readily confirmed by measuring circulating insulin-like growth factor-I concentrations that correlate with the integrated 24-hour GH secretion levels. ${ }^{5}$

The presence of different $\mathrm{GH}$ isoforms in patients with gigantism/acromegaly may represent a diagnostic problem. ${ }^{47,48}$ A greater sensitivity of the $\mathrm{GH}$ assay may facilitate the distinction between patients and healthy volunteers, as shown by the use of a chemiluminescence GH assay. ${ }^{13,57}$ It may also help in demonstrating the persistence of GH hypersecretion after surgery or during medical therapy. In case of clinical and laboratory findings indicative of a GHproducing adenoma, pituitary MR imaging must be performed to localize and characterize the tumor.

\section{TREATMENT}

\section{Management of Craniopharyngiomas}

In small intrasellar or enclosed tumors, total resection is most easily achieved, and adjunctive radiotherapy is unnec- essary. ${ }^{24}$ Radiotherapy is required in cases of incomplete tumor removal, which occurs frequently with extrasellar craniopharyngiomas (the majority of cases). ${ }^{27,28,40,53}$ Surgical morbidity depends on tumor size and invasiveness, the experience of the surgeon, and the route of surgical approach. The risk of hypothalamic damage is significantly greater in large invasive tumors treated via the transcranial approach. Near-total excision of the tumor by an experienced pituitary surgeon sparing the hypothalamus, carotid arteries, and visual apparatus, followed by fractionated radiotherapy, provides the best hope of low long-term morbidity and longer survival. ${ }^{28,29,40}$ Regardless of the approach, the incidence of endocrine dysfunction is high following surgical treatment, ${ }^{29}$ although it is lower after the transsphenoidal approach. ${ }^{24}$ Localized intracavity yttrium, phosphorus-32, and other radioactive implants, given as additional treatment, have proven useful for recurrent tumors with a predominant cystic component. Hyperfractionated multiportal stereotactic radiotherapy and gamma knife radiosurgery are promising therapeutic adjuncts to standard radiotherap, due to their potential ability to reduce treatment-associated morbidity in this condition. In children, however, the benefit of any additional radiotherapy treatment should be balanced against the relatively high risk of inducing hypopituitarism later in life..$^{24}$

\section{Management of PRL-Secreting Adenomas}

In the absence of complications that need immediate surgery, such as rapidly progressing visual loss, hydrocephalus, or a cerebrospinal fluid leak, pharmacotherapy with dopamine agonists should be considered the first treatment approach. Treatment with dopamine agonists is effective in normalizing PRL levels and shrinking the tumor mass in the majority of adult patients with prolactinoma. ${ }^{16,45,56} \mathrm{In}$ children and adolescents, bromocriptine has been used successfully by several investigators to decrease tumor volume. ${ }^{9}$

Quinagolide and cabergoline are two selective dopamine receptor subtype-2 agonists that have also been reported to be effective in reducing PRL secretion and tumor size in adult patients with prolactinoma, even in those previously shown to be poorly responsive to or intolerant of bromocriptine. ${ }^{14}$ Cabergoline in particular has received attention for its tolerability and high compliance rates ${ }^{7,17,56}$ and has been shown to be effective also in patients whose tumors are poorly responsive or resistant to bromocriptine. Cabergoline has a longer halflife than bromocriptine, and it normalizes serum PRL levels and restores gonadal function in the majority of patients with microprolactinomas. ${ }^{16,45}$ Its convenient weekly administration also makes it an excellent therapeutic alternative in children with prolactinomas. ${ }^{56}$

\section{Management of $C D$}

Transsphenoidal resection is the treatment of choice for ACTH-secreting adenomas. Surgical removal is successful in the majority of children, with initial remission rates of 70 to $98 \%$ and long-term cure rates of 50 to $98 \%$ in most studies. ${ }^{41,48}$ The success rate decreases when the patients are followed for more than 5 years, and the outcome cannot be predicted by pre- or postoperative tests. ${ }^{41,42}$ The morbidity is low when the procedure is performed by an experienced 
neurosurgeon. Transsphenoidal microsurgery is considered successful when it is followed by remission of signs and symptoms of hypercortisolism and by normalization of laboratory values. Surgery is usually followed by adrenal insufficiency, and patients require hydrocortisone replacement for 6 to 12 months. After normalization of cortisol levels, resumption of normal growth or even catch-up growth can be observed. Generally, the patient's final height is compromised compared with their target height. ${ }^{38}$ Some children, however, do achieve a normal final stature. ${ }^{31}$

The choice of treatment modality in patients who have relapses after transsphenoidal adenomectomy is still controversial. Some authors recommend repeated surgery, ${ }^{26}$ whereas others favor radiation therapy. ${ }^{19,29}$ Radiotherapy with or without concomitant mitotane treatment may be indicated in patients with macroadenoma. ${ }^{29}$ Although surgery can induce panhypopituitarism or permanent diabetes insipidus, hypothalamic-pituitary dysfunction is an early and frequent complication of radiation. ${ }^{22,54}$ Bilateral adrenalectomy may be the last therapeutic option in case of failure of both surgery and radiotherapy. Stereotactic radiosurgery with the gamma knife and linear accelerator includes promising new modalities that minimize the toxic effects of radiation on the brain, while still controlling tumor growth and ACTH secretion..$^{54}$

\section{Management of GH-Secreting Adenomas}

The objectives in the treatment of excess GH are tumor removal with resolution of its mass effect, restoration of normal basal and stimulated GH secretion, relief of symptoms caused by GH excess, and prevention of disease sequelae (that is, hypertension, insulin resistance, diabetes mellitus, and lipid abnormalities). The currently available treatment options for acromegaly include surgery, radiotherapy, and pharmacological suppression of GH levels by means of dopamine agonists or somatostatin analogs. Transsphenoidal resection remains the first treatment choice for GH-secreting tumors. In the case of macroadenomas, particularly when they exhibit extrasellar growth, persistent postoperative hypersecretion of GH occurs frequently. In most surgical series, only approximately $60 \%$ of patients with acromegaly achieve normal GH levels, but the success rate improves when the surgeon is a specialist in pituitary surgery. ${ }^{3,39}$ In pediatric patients with gigantism, transsphenoidal surgery was found to be as safe as it is in adults. ${ }^{2}$

\section{Management of Clinically Nonfunctioning Adenomas}

The first approach to these adenomas is transsphenoidal resection to debulk the tumor and decompress parasellar structures. ${ }^{36}$ As in the other histological types of adenoma, surgery has a low morbidity rate and leads to an improvement of visual symptoms in the majority of cases..$^{35}$ The recent development of the endoscopic transsphenoidal approach to the pituitary, ${ }^{30,12}$ which has indications similar to conventional transsphenoidal microsurgery, overcomes many of the potential problems associated with the surgical route, due to its minimal invasiveness. This procedure involves no fractures of the facial bones or sublabial incisions. Furthermore, a wider surgical view of the operating field is obtained, which potentially improves the likelihood of a better and safer tumor removal. Endoscopic treatments can result in shorter hospitalization times and a rapid recovery for the child..$^{12,30}$

\section{CONCLUSIONS}

The management of pituitary adenomas and other sellar lesions must account for both the endocrine and neurological sequelae of these tumors. Patients require thorough pre- and posttreatment evaluation by neuroendocrinologists, neurosurgeons, neuroophthalmologists, and neuroradiologists. Medical treatment is the primary therapy for prolactinomas and recent advances have brought forward the expectation of effective pharmacotherapy for GH adenomas as well. Transsphenoidal surgery offers effective relief of mass effect and not only restoration but the preservation of normal endocrine function in the majority of patients. Radiation therapy can offer remission for some patients with medically and surgically refractory tumors, but patients must be observed closely for evidence of radiation necrosis and the presence of new endocrinopathies. With improved understanding of the molecular pathogenesis, future therapy will treat these tumors more effectively.

\section{References}

1. Abe T, Lüdecke DK, Saeger W: Clinically nonsecreting pituitary adenomas in childhood and adolescence. Neurosurgery 42:744-751, 1998

2. Abe T, Tara LA, Lüdecke DK: Growth hormone-secreting pituitary adenomas in childhood and adolescence: features and results of transnasal surgery. Neurosurgery 45:1-10, 1999

3. Ahmed S, Eldsheikh, Stratton IM, et al: Outcome of transsphenoidal surgery for acromegaly and its relationship to surgical experience. Clin Endocrinol 50:561-567, 1999

4. Akimura T, Kamleda H: Infrasellar craniopharyngioma. Neuroradiology 31:180-183, 1989

5. Barkan L, Beitins IZ, Kelch RP: Plasma insulin-like growth factor-I/somatomedin-C in acromegaly: correlation with the degree of growth hormone hypersecretion. J Clin Endocrinol Metab 67:69-73, 1988

6. Beck-Peccoz P, Bruckner-Davis F, Persani L, et al: Thyrotropinsecreting pituitary tumors. Endocr Rev 17:610-638, 1996

7. Biller BM, Molitch ME, Vance ML: Treatment of prolactinsecreting macroadenoma with once-a week dopamine agonist cabergoline. J Clin Endocrinol Metab 81:2338-2343, 1996

8. Blackwell RE, Younger BJ: Long-term medical therapy and follow up of pediatric adolescent patients with prolactin-secreting macroadenomas. Fertil Steril 45:713-716, 1986

9. Boop FA, Teo C, Pihoker K: Pediatric pituitary tumors, in Krisht AF, Tindall GT (eds): Comprehensive Management of Pituitary Disorders. Philadelphia: Lippincott Williams \& Wilkins, 1999, pp 315-326

10. Brucker-Davis F, Oldfield EH, Skarulis MC, et al: Thyrotropinsecreting pituitary tumors: diagnostic criteria, thyroid hormone sensitivity, and treat-ment outcome in 25 patients followed at the National Institute of Health. J Clin Endocrinol Metab 84: 476-486, 1999

11. Bunin GR, Surawicz TS, Witman PA, et al: The descriptive epidemiology of craniopharyngioma. J Neurosurg 89:547-551, 1998

12. Cappabianca P, Alfieri A, Colao A, et al: Endoscopic endonasal transsphenoidal approach: an additional reason in support of surgery in the management of pituitary lesions. Skull Base Surg 9: 109-117, 1999

13. Chapman IM, Hartman ML, Straume M, et al: Enhanced sensitivity growth hormone $(\mathrm{GH})$ chemiluminescence assay reveals lower postglucose nadir GH concentrations in men than in women. J Clin Endocrinol Metab 78:1312-1319, 1994

14. Colao A, Annunziato L, Lombardi G: Treatment of prolactinomas. Ann Med 30:452-459, 1998 
15. Colao A, Loche S, Cappabianca P, et al: Pituitary adenomas in children and adolescents. Clinical presentation, diagnosis and therapeutical strategies. J Clin Endocrinol Metab 83: 2777-2780, 1998

16. Colao A, Lombardi G: Growth Hormone and Prolactin excess. Lancet 352:1455-1461, 1998

17. Colao A, Lombardi G, Annunziato L: Cabergoline. Expert Opinion Pharmacother 1:555-574, 2000

18. Colao A, Merola B, Ferone D, et al: Acromegaly. J Clin Endocrinol Metab 82:2777-2781, 1997

19. Devoe DJ, Miller WL, Conte FA: Long-term outcome in children and adolescents after transsphenoidal surgery for Cushing's disease. J Clin Endocrinol Metab 82:3196-3202, 1997

20. Dissaneevate P, Warne GL: Hyperprolactinaemia and pituitary adenomas in adolescence. J Pediatr Endocrinol Metab 11: 531-541, 1998

21. Di Somma C, Pivonello R, Loche S: Effect of 2 years of cortisol normalization on the impaired bone mass and turnover in adolescent and adult patients with Cushing's disease. Clin Endocrinol 58:302-308, 2003

22. Estrada J, Boronat M, Mielgo M, et al: The long term outcome of pituitary irradiation after unsuccessful transsphenoidal surgery in Cushing's disease. N Engl J Med 336:172-177, 1997

23. Eugster EA, Pescovitz OH: Gigantism. J Clin Endocrinol Metab 84:4379-4384, 1999

24. Fahlbusch R, Honegger J, Paulus W, et al: Surgical treatment of craniopharyngiomas: experience with 168 patients. J Neurosurg 90:237-250, 1999

25. Freeman M, Kessler R, et al: Craniopharyngioma: CT and MR imaging in nine cases. J Comput Assist Tomogr 5:810-814, 1987

26. Friedman RB, Oldfield EH, Nieman LH, et al: Repeat transsphenoidal surgery for Cushing's disease. J Neurosurg 71: 520-527, 1989

27. Hayward R: The present and future management of childhood craniopharyngioma. Childs Nerv Syst 15:764-776, 1999

28. Hetelekidis S, Barnes PD, Tao ML, et al: 20-year experience in childhood craniopharyngioma. Int J Radiat Oncol Biol Phys 27:189-195, 1993

29. Jennings AS, Liddle GW, Orth DN: Results of treating childhood Cushing's disease with pituitary irradiation. N Engl J Med 297:957-962, 1977

30. Jho HD, Carrau RL: Endoscopic endonasal transsphenoidal surgery: experience with 50 patients. J Neurosurg 87:44-51, 1997

31. Johnston LB, Grossman AB, Plowman PN, et al: Normal final height and apparent cure after pituitary irradiation for Cushing's disease in childhood: long-term follow-up of anterior pituitary function. Clin Endocrinol 48:663-667, 1998

32. Katnelson L, Alexander JM, Klibanski A: Clinically nonfunctioning pituitary adenomas. J Clin Endocrinol Metab 76: 1089-1094, 1993

33. Kunwar S, Wilson CB: Pediatric pituitary adenomas. J Clin Endocrinol Metab 84:4385-4389, 1999

34. Lafferty AR, Chrousos GP: Pituitary tumors in children and adolescents. J Clin Endocrinol Metab 84:4317-4323, 1999

35. Laws ER, Scheithauer BW, Groover RV: Pituitary adenomas in childhood and adolescence. Prog Exp Tumor Res 30:359-361, 1987

36. Laws ER Jr: Transsphenoidal approach to pituitary lesions, in Schmidek HH, Sweet WH (eds): Operative Neurosurgical Techniques: Indications, Methods and Results. Philadelphia: WB Saunders, 1995, pp 283-292

37. Leinung MC, Kane LA, Scheithauer BW, et al: Long term follow-up of transsphenoidal surgery or the treatment of Cushing's disease in childhood. J Clin Endocrinol Metab 80:2475-2479, 1985

38. Lienhardt A, Grossman AB, Dacie JE, et al: Relative contributions of inferior petrosal sinus sampling and pituitary imaging in the investigation of children and adolescents with ACTH-dependent Cushing's syndrome. J Clin Endocrinol Metab 86: 5711-5714, 2001

39. Lissett CA, Peacey SR, Laing I, et al: The outcome of surgery for acromegaly: the need for a specialist pituitary surgeon for all types of growth hormone $(\mathrm{GH})$ secreting adenoma. Clin Endocrinol 49:653-657, 1998

40. Lyen KR, Grant DB: Endocrine function, morbidity, and mortality after surgery for craniopharyngioma. Arch Dis Child 57: 837-841, 1982

41. Magiakou MA, Mastorakos G, Gomez MT, et al: Suppressed spontaneous and stimulated growth hormone secretion in patients with Cushing's disease before and after surgical cure. J Clin Endocrinol Metab 78:131-137, 1994

42. Magiakou MA, Mastorakos G, Oldfield EH, et al: Cushing's syndrome in children and adolescents. Presentation, diagnosis, and therapy. N Engl J Med 331:629-636, 1994

43. Matthews FD: Intraventricular craniopharyngioma. AJNR 4: 984-985, 1983

44. Mindermann T, Wilson CB: Pediatric pituitary adenomas. Neurosurgery 36:259-269, 1995

45. Molitch ME, Thorner MO, Wilson C: Management of prolactinomas. J Clin Endocrinol Metab 82:996-1000, 1997

46. Newell-Price J, Trainer P, Besser M, et al: The diagnosis and differential diagnosis of Cushing's syndrome and pseudo-Cushing's states. Endocr Rev 19:647-672, 1998

47. Ng LL, Chasalow FI, Escobar O, et al: Growth hormone isoforms in a girl with gigantism. J Pediatr Endocrinol Metab 12:99-106, 1999

48. Norris JS, Pavaresh M, Afshar F: Primary transsphenoidal microsurgery in the treatment of craniopharyngiomas. Br J Neurosurg 12:305-312, 1998

49. Oldfield EH, Doppman JL, Nieman LK: Petrosal sinus sampling with and with-out corticotropin-releasing hormone for the differential diagnosis of Cushing's syndrome. N Engl J Med 325:897-905, 1991

50. Partington MD, Dudley HD, Laws ER, et al: Pituitary adenomas in childhood and adolescence. Results of transsphenoidal surgery. J Neurosurg 80:209-216, 1994

51. Pusey E, Kortman KE, Flannigan BD, et al: MR of craniopharyngiomas: tumor delineation and characterization. AJR 149: 383-388, 1987

52. Sanford RA: Craniopharyngioma: results of survey of the American Society of Pediatric Neurosurgery. Pediatr Neurosurg 21 (Suppl 1):39-43, 1994

53. Scott RM, Hetelekidis S, Barnes PD, et al: Surgery, radiation, and combination therapy in the treatment of childhood craniopharyngioma-a 20-year experience. Pediatr Neurosurg 21 (Suppl 1):75-81, 1994

54. Sheehan JM, Vance ML, Sheehan JP, et al: Radiosurgery for Cushing's disease after failed transsphenoidal surgery. J Neurosurg 93:738-747, 2000

55. Sklar CA: Craniopharyngioma: endocrine abnormalities at presentation. Pediatr Neurosurg 21 (Suppl):18-20, 1994

56. Webster J, Piscitelli G, Polli A, et al: A comparison of cabergoline and bromocriptine in the treatment of hyperprolactinemic amenorrhea. N Engl J Med 331:904-909, 1994

57. Whitehead EM, Shalet SM, Davies D, et al: Pituitary gigantism: a disabling condition. Clin Endocrinol 17:271-277, 1982

Manuscript received May 10, 2005

Accepted in final form May 24, 2005.

Address reprint requests to: Edward R. Laws Jr., M.D., Department of Neurological Surgery, University of Virginia, PO Box 800212, Charlottesville, Virginia 22908-00212. email: el5g@ virginia.edu 